\title{
Site response estimation at Mirandola by virtual reference station
}

\author{
Giovanna Laurenzano $^{1,2}$ (D) Enrico Priolo ${ }^{1,2} \cdot$ Marco Mucciarelli $^{1,2} \cdot$ \\ Luca Martelli ${ }^{3} \cdot$ Marco Romanelli ${ }^{1,2}$
}

Received: 28 January 2016/ Accepted: 19 October 2016/Published online: 19 November 2016

(C) The Author(s) 2016. This article is published with open access at Springerlink.com

\begin{abstract}
In this paper, we address the issue of evaluating the seismic site response for sites located on large alluvial plains, for which no reference sites can be identified, but some earthquakes can be simultaneously recorded at both surface and depth. In the proposed method, surface and borehole records are firstly used to assess the local 1D velocity model, then a model representing a virtual reference rock site is defined, and finally the site spectral amplification is calculated through numerical modeling. The effectiveness of the method is demonstrated at the site of Mirandola (Italy). This site is located in an area which suffered heavy damage during the seismic sequence that started in Northern Italy with the Mw = 5.8 event on May 20th, 2012. That time, the site hosted an accelerometer of the National Accelerometric Network, which recorded the whole sequence. A new station, named MIRB (MIRandola Borehole), was installed during 2014; it is equipped with three accelerometric sensors deployed at surface, 31 and $126 \mathrm{~m}$ depth, respectively. The results of this study evidence that Mirandola is characterized by an amplification level consistent with that of a class-C soil for up to a period of about $0.45 \mathrm{~s}$, while for higher periods, the amplification lays between class- $\mathrm{B}$ and $\mathrm{C}$ soils.
\end{abstract}

Keywords Site response $\cdot$ Borehole data $\cdot$ Reference site $\cdot$ Mirandola

\section{Introduction}

Given the significant contribution of the local site conditions to the seismic hazard, it is common practice to evaluate the seismic input considering rock conditions and modifying the results by applying the site-specific response. The determination of the site response

Giovanna Laurenzano

glaurenzano@inogs.it

1 Istituto Nazionale di Oceanografia e di Geofisica Sperimentale (OGS) - Sezione Scientifica Centro di Ricerche Sismologiche (CRS), Trieste, Italy

2 Istituto Nazionale di Oceanografia e di Geofisica Sperimentale (OGS) - Sezione Scientifica Centro di Ricerche Sismologiche (CRS), Udine, Italy

3 Regione Emilia-Romagna, Servizio Geologico, Sismico e dei Suoli, Bologna, Italy 
plays therefore a critical role in the mitigation of the seismic risk and there still is a debate on how to account for it in the seismic codes at best (Pitilakis et al. 2015).

A rather comprehensive description of the seismic site response is given by the spectral amplification, i.e. the ratio between the amplitude spectra of the observed ground motion and the motion that would be expected at the same location if there were no site effect. The spectral amplification is usually determined directly by the well-established Reference Site Spectral Ratio-RSSR method (Borcherdt 1970), which implies the recording of the earthquake ground motion both at the specific site and at a nearby reference site, where the site effects are negligible. A critical precondition for the application of RSSR is the availability of a reference site in the proximity of the site under investigation.

This paper presents the results obtained from a geophysical-seismological study aimed at characterizing the site response in the town of Mirandola in Emilia-Romagna region (Northern Italy).

Being Mirandola located on the alluvial deposits of the Po plain far away from surface rock sites, the standard RSSR approach with a reference site at surface is inapplicable and we adopt an original procedure which allows us to estimate the site response from borehole data and other geophysical surveys. Since the seismic action is in practice calibrated on ground motion recordings collected at surface (at the bedrock outcropping), we evaluate the spectral amplification in respect to a virtual surface rock site, which mimics the conditions of the reference site considered in the building codes (in our case the Eurocode8, class-A soil).

Mirandola is one of the towns that suffered significant damages during the 2012 Emilia seismic sequence (Tertulliani et al. 2012), which was characterized by two larger events with $\mathrm{Mw}=5.8$ on May 20th and with $\mathrm{Mw}=5.6$ on May 29th (ISIDe Working Group, INGV 2010), respectively.

Immediately after the occurrence of the Mw 5.8 earthquake on May 20, 2012, several teams of seismologists from different institutions went to the epicentral area and deployed rapid-response seismic networks in order to improve the monitoring during the seismic sequence and to evaluate the seismic response at the instrumented sites (Moretti et al. 2012). As the seismic sequence continued, the field activity was focused not only on monitoring the seismic events but also on collecting and analyzing the geological and geophysical data in order to identify the seismogenic structures, to define the level of damage, and to study the effects of the earthquakes on the environment. A number of works were published on this topic, see for example the special issue of the Annals of Geophysics, entitled The Emilia (northern Italy) seismic sequence of May-June, 2012: preliminary data and results (http://www.annalsofgeophysics.eu/). In addition, the EmiliaRomagna regional government undertook some microzonation studies (Martelli et al. 2013; Martelli and Romani 2013).

In this context, several geophysical investigations have been carried out in Mirandola, such as the velocity profile obtained from cross-hole and down-hole tests, ESAC and noise HVSR data (Paolucci et al. 2015; Gallipoli et al. 2014). However, the essential step for our purposes consists in the installation of three-component seismic sensors in two adjacent boreholes that was performed in June 2014. The deepest sensor reaches the bedrock and allows observing the ground motion not affected by the local soil conditions. A cross-hole (CH) survey (Martelli and Romani 2013) provides the Vs profile down to the bedrock.

Within the InterPacific project, Mirandola was also chosen as one of the test-sites for comparing the effectiveness of invasive and non-invasive methods (such as cross-hole and down-hole tests, versus surface-waves or refraction seismics methods) for seismic site characterization (Garofalo et al. 2016a, b). For the Mirandola site, the stratigraphic profile 
of the Emilia Romagna Region (Martelli and Romani 2013) was assumed as a reference and the cross-hole $V s$ profile was validated by the measurements carried out for the project (Garofalo et al. 2016a, b).

Moreover, for the area affected by the 2012 seismic sequence, some studies provide regional velocity models (for example Malagnini et al. 2012; Vuan et al. 2011; Govoni et al. 2014), while others give evidence of the seismic response at some sites within the epicentral area (Priolo et al. 2012) or compare the ground-motion observation with prediction equations for soft soils (Barnaba et al. 2014).

Thanks to the seismic instrumentation installed within the two boreholes we were able to proceed to the evaluation of the spectral amplification at the site of Mirandola. The ground motion recorded in borehole actually revealed strong interference effects of the waves reflected from surface, therefore the borehole recordings are not fit to be used directly in RSSR. In order to estimate the spectral amplification we adopt an alternative approach which makes use of numerical modeling and uses earthquake recordings simultaneously acquired at surface and depth, respectively, to define the local velocity model (Laurenzano et al. 2013a, b).

In this paper, we first provide some insight to the theoretical basis of our approach. Then we describe the site, the station installation and the available data in detail. Next we present the application of the analysis of the interferences in borehole recordings to the validation of the $V s$ profile provided by the $\mathrm{CH}$ survey. Finally we evaluate the spectral amplification with respect to a virtual reference site with class-A soil and compare it to the spectral amplification provided in the NTC-2008 Italian building code (NTC 2008).

\section{Method}

Seismic site response is usually described using the spectral amplification, i.e. the ratio between the amplitude spectrum of the earthquake waveforms recorded at the site and those observed at a nearby site located on rock (Borcherdt 1970).

Steidl et al. (1996) questioned about the nature of the reference sites and demonstrated that surface sites on bedrock are often characterized by a non-neutral spectral response at frequencies of engineering interest. They suggested the use of reference sites in borehole providing that the interference effects of the reflections from the surface are properly taken in consideration. The usage of the reference site in borehole seems in any case unavoidable, when the studied area is in the middle of an alluvial plain with no bedrock outcrop in the neighborhood.

However, since in our case the spectral amplification has to be evaluated for a seismic action applied (or recorded) at a surface rock site, which is not available at Mirandola, we introduce a virtual rock surface site, which mimics the conditions of the reference site considered by building codes (in our case the Eurocode8, class-A soil). To this aim we make use of numerical modeling, applied to a local velocity model validated with an analysis of the interference effects observed in the borehole recordings.

The seismograms recorded in borehole are the result of the superposition of an up-going wavefield coming from the earthquake source and a down-going wavefield reflected from the surface, with the addition of surface waves at later times. At depth $z$, the interference of the up-going and down-going wavefields generates notches in the recorded spectra. This is true especially for events close to the receiver, since the wavefield is mainly composed by body waves and its direction of propagation is close to the vertical. On the other hand the seismograms recorded at surface represent to a good approximation of the incoming 
wavefield. The ratio between the Fourier amplitude spectra of waveforms recorded at surface and at depth $z$ may be used to estimate the wavefield interference at the receiver depth. This function is called interferometric function.

In the simple case of a homogeneous medium, it can be shown that the interferometric function for a vertically incident plane wave features peaks at frequencies:

$$
\mathrm{f}_{\mathrm{n}}=\frac{(2 \mathrm{n}+1) \cdot \mathrm{v}}{4 \mathrm{z}}
$$

where $n=0,1,2,3, \ldots$; and $z=$ recording depth and $\mathrm{v}=$ soil velocity.

The distance between peaks is regular and is controlled by the following formula:

$$
\Delta \mathrm{f}=\frac{\mathrm{v}}{2 \mathrm{z}}
$$

In the more realistic case of an inhomogeneous medium, the interferometric function is very sensitive to model variations in the velocity and thickness of the layers above the receiver located at depth and it cannot be written in simple form.

It is important to point out, that the waveform recorded at the deep receiver contains a significant contribution from the down-going wavefields reflected by the free surface and other interfaces above the receiver. Therefore it cannot be regarded as the waveform representing the free field record of a rock reference site. It comes out that the interferometric function does not represent the site amplification; even in the case the deep receiver is located in the bedrock. On the other hand, being the interferometric function highly sensitive to the seismic velocity distribution in the layers above the buried receiver, it represents a very reliable tool to constrain the velocity model down to the receiver depth.

In this study, we used the interferometric function in order to validate and refine the velocity model of Mirandola site. The validation consists in the comparison of the empirical interferometric function obtained from a set of recordings at surface and in the borehole with synthetic interferometric functions obtained from a set of velocity models defined on the base of the available geophysical studies.

The comparison is made by a misfit function MF based on the mean square difference between the experimental and synthetic interferometric functions:

$$
\mathrm{MF}=\sum_{i=1}^{N} \frac{\left(I F_{i}^{(\exp )}-I F_{i}^{(s y n)}\right)^{2}}{N}
$$

where, $I F^{(e x p)}$ and $I F^{(s y n)}$ are the experimental and synthetical interferometric functions, respectively.

The site amplification function is evaluated as the spectral ratio between the synthetic seismograms computed at the site for two velocity models. One is the velocity model corresponding to the minimum MF and the other represents the virtual rock site corresponding to EC-8 class-A soil. Both the models have in common the deep structure (i.e. below the buried receiver depth).

\section{Description of the site and station installation}

Particular interest for the Mirandola site has been sparked by the analysis of the accelerometric data collected during the seismic sequence of Finale Emilia of May 2012. In fact, the station of Mirandola (named MIRA) was the closest station of the Italian Strong 
Motion Network-Rete Accelerometrica Nazionale (RAN, http://www.protezionecivile.it) to both the epicenters of the 20 and 29 May 2012 shocks, and it recorded very high acceleration peaks (almost $0.9 \mathrm{~g}$ on the vertical component during the 29 May event). This RAN station is located just north of the anticline axis at the top of the southernmost thrust front of the Ferrara Fold (Pieri and Groppi 1981). In order to characterize the subsurface from the stratigraphic, geotechnical and geophysical point of view, the Geological Seismic and Soil Survey of the Emilia-Romagna Region, performed two drillings, $126 \mathrm{~m}$ deep and at distance of few meters each other. Both drillings reached the seismic bedrock, which consists of consolidated mudstones with interbedded sands, referring to the middle Pliocene, at depth of $113 \mathrm{~m}$. A cross-hole survey was performed in order to define the stratigraphic profile and measure the seismic shear-wave velocity $V s$. Later, a third $31 \mathrm{~m}$ deep drilling was realized in the neighborhood of the two boreholes.

A new accelerometric station named MIRB (MIRandola Borehole) was realized close to MIRA with sensors in borehole during 2014. In detail, at the first drilling, $126 \mathrm{~m}$ deep, the station is equipped with a six channel, 24-bit resolution Sara (www.sara.pg.it) SL06 digitizer and two Sara Force Balance accelerometers SA10, deployed one at the surface and one at the hole bottom, respectively. At the $31 \mathrm{~m}$ deep drilling, a three channel Sara SL06 digitizer equipped with another SA10 accelerometer deployed at the hole bottom, was installed. For both boreholes, the casing was cemented into the borehole and the sensors were coupled to the casing wall by a spring system. The misalignment angle correction have been estimated in $120^{\circ}$ and $7^{\circ}$ for the borehole sensors at $\mathrm{z}=-31$ and $-126 \mathrm{~m}$ respectively, using the sensor at the surface as a reference (Mucciarelli et al. 2015).

The two boreholes lay at distance of less than $4 \mathrm{~m}$ one from another, and their geographical coordinates are respectively: $44^{\circ} 52^{\prime} 38.91^{\prime \prime} \mathrm{N}, 11^{\circ} 3^{\prime} 46.10^{\prime \prime} \mathrm{E}, 17 \mathrm{~m}$.a.s.l. and $44^{\circ} 52^{\prime} 38.80^{\prime \prime} \mathrm{N}, 11^{\circ} 3^{\prime} 46.10^{\prime \prime} \mathrm{E}, 17 \mathrm{~m}$.a.s.l. Data are acquired in continuous mode with a sampling rate of $100 \mathrm{~Hz}$. The station is designed to operate autonomously with the adoption of a photovoltaic system and a dedicated router-modem for remote transmission.

The data from MIRB station are stored in two archive systems belonging to OGS-The National Institute of Oceanography and Experimental Geophysics, i.e. the archive named NISBAS-the Network of Italian Surface-Borehole Accelerometers and Seismometers (http://nisbas.crs.inogs.it, Mucciarelli et al. 2015), which is devoted to organize, storage and provide access of data recorded by stations equipped with both surface and borehole sensors, and the archive named OASIS-the OGS Archive System of Instrumental Seismology (http://oasis.crs.inogs.it, Priolo et al. 2015). The user can retrieve detailed information about the seismological station as well as download generic pieces of waveforms taken from the stream of continuous recordings. Data are freely available.

\section{Validation of the geophysical 1D model of Mirandola}

The correct definition of the seismic velocities in the uppermost layers is essential for the computation of the seismic response of the Mirandola site. As already discussed, the velocity model validation is performed by comparing the empirical interferometric function obtained from earthquake waveforms recorded simultaneously at surface and depth to the interferometric function calculated at the same receivers through numerical modeling. Interferometric functions are obtained as the mean of the ratios between the Fourier amplitude spectra of the waveform at surface and at the two different depths. The numerical computation of the waveforms was performed using the Wavenumber 
Integration Method (WIM-Herrmann 1996a, b), a method that solves the 3D full wave equation in a horizontally layered medium.

\subsection{Experimental data}

The experimental interferometric functions were calculated using the recordings of 25 events occurred in the area during the period June 2014-October 2015, with magnitude between 2.1 and 3.7. Table 1 lists date, location and magnitude of the selected events (ISIDe Working Group, INGV 2010), while Fig. 1 shows their location.

We retrieved the accelerograms for the selected events from NISBAS (http://nisbas.crs. inogs.it). Since the instrumentation installed at different depths is the same and we were interested only to the spectral ratios, we didn't need to apply any instrumental correction to the recordings. Therefore we worked directly with data in counts.

The processing of data consists in:

- Selection of the time windows for both the surface and depth recordings: only the body waves contribution is selected since it is the only that is interested by interference;

- Applying a baseline and a tapering correction to the time windows;

Table 1 List of the 25 events recorded at MIRB and used for the computation of the empirical interferometric function
From left to right: date, latitude, longitude, depth $(\mathrm{km})$ and magnitude (from: ISIDe Working Group, INGV 2010)

\begin{tabular}{lllrl}
\hline Event & Lat & Lon & Depth & M \\
\hline 20140619224343 & 44.918 & 11.054 & 7.1 & 2.8 \\
20140723222636 & 44.895 & 11.283 & 24.7 & 2.2 \\
20140805050425 & 44.902 & 11.290 & 9.7 & 2.5 \\
20140807230441 & 44.891 & 11.286 & 9.8 & 2.1 \\
20140808220034 & 44.876 & 11.204 & 5.9 & 2.1 \\
20140828174919 & 45.656 & 10.666 & 10.0 & 3.6 \\
20141005070923 & 44.614 & 11.062 & 34.9 & 2.5 \\
20150105080829 & 44.899 & 11.248 & 8.0 & 2.7 \\
20150201184422 & 44.886 & 11.280 & 9.8 & 2.3 \\
20150215223503 & 44.915 & 10.946 & 8.4 & 2.5 \\
20150217194253 & 44.177 & 11.406 & 8.4 & 3.7 \\
20150224223813 & 44.100 & 12.041 & 22.4 & 3.3 \\
20150304000004 & 43.604 & 11.175 & 9.2 & 3.7 \\
20150311090248 & 44.895 & 11.265 & 9.7 & 2.4 \\
20150401045811 & 44.180 & 11.710 & 21.4 & 3.2 \\
20150718152639 & 44.276 & 10.953 & 8.9 & 3.0 \\
20150721230724 & 44.056 & 10.981 & 57.2 & 3.1 \\
20150722125743 & 44.156 & 10.894 & 21.5 & 3.7 \\
20150801204751 & 45.903 & 10.773 & 5.2 & 3.7 \\
20150806205212 & 44.927 & 11.239 & 9.4 & 2.6 \\
20150818201002 & 45.905 & 11.902 & 7.3 & 3.6 \\
20150823171052 & 44.893 & 11.290 & 8.8 & 2.1 \\
20150824034353 & 44.259 & 11.939 & 21.7 & 3.5 \\
20150824220611 & 44.879 & 10.570 & 31.6 & 2.6 \\
20151020103550 & 44.897 & 11.108 & 6.7 & 3.5 \\
\hline & & & &
\end{tabular}


- Computing the mean interferometric function as the mean ratio between surface and depth smoothed spectra of all the recordings;

Smoothing is applied by a moving average method. Since the signal-to-noise-ratio of the recordings was very good in the frequency range of engineering interest between 0.5 and $20 \mathrm{~Hz}$, no filters were applied.

Figure 2 shows as an example the recordings of a local earthquake $(\mathrm{M}=3.5)$ at station MIRB. One can observe that: (1) waveforms of receivers located at depth feature a smaller amplitude; and, (2) PGA increases of an average factor of 3.4 and 2.7 moving from deepest and intermediate sensors to surface, respectively. Figure 3 shows the Fourier amplitude spectra of the data recorded at the surface and the two depths for two different events (left and right panels, respectively). The spectra are smoothed to emphasize the spectral notches. Note that while the spectra feature different shapes and frequency content, the spectral notches persist at the same frequencies.

Figure 4 shows the spectral ratios computed between the data recorded at surface and depth, for the two depths of 31 and $126 \mathrm{~m}$, respectively. The thin grey curves refer to the 25-recorded events, taking the geometrical average of the two horizontal components, while the thick red curve represents the arithmetic mean of the whole family. The coherence among the interferometric functions estimated for the different events demonstrate the stability of the interferometric function for the considered range of magnitudes,

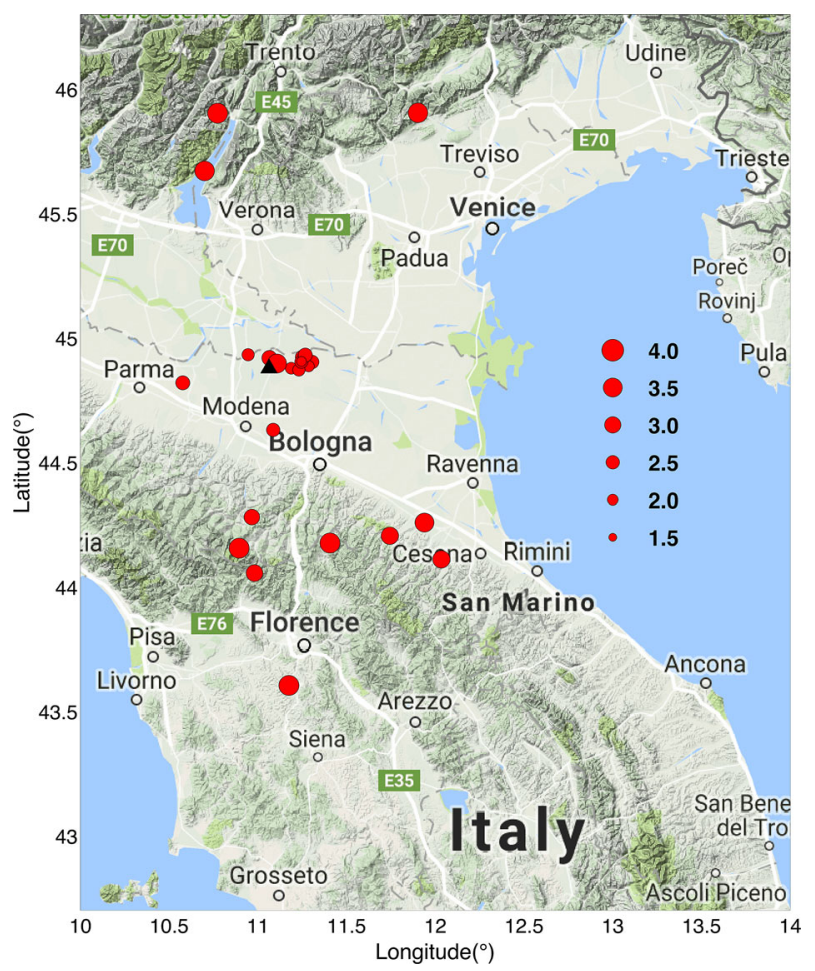

Fig. 1 Map of the location of the 25 earthquakes used in the study (red circles) and of Mirandola station MIRB (black triangle) 
epicentral distances and azimuths. For the shallower receiver, the peaks are at 2.1, 5.3, 8.6, 12.3 and $16 \mathrm{~Hz}$, while for the deeper receiver the peaks are located at $0.75,2.1,3.1,4.4$, 5.6, 7.2, $9.7 \mathrm{~Hz}$.

\subsection{Forward modeling and validation}

The validation of the velocity profile is accomplished by means of the comparison of the experimental interferometric functions with those obtained by numerical modeling. The synthetic interferometric function allows considering (and validating) the model down to the deeper receiver depth (in this case $-126 \mathrm{~m}$ ) and is influenced only by layer thickness and $V s$, and not by other parameters.

We computed synthetic seismograms using WIM (Herrmann 1996a, b) for a plane $\mathrm{S}$-wave propagating upwards for three depth values corresponding to actual sensors, i.e. surface, $-31 \mathrm{~m}$, and $-126 \mathrm{~m}$, respectively and for a set of different velocity models built on the base of the available geophysical studies.

After the occurrence of the 2012 Emilia sequence, a series of investigation have been performed at the site of Mirandola, namely: a down-hole test down to $30 \mathrm{~m}$; ESAC and HVSR inversion down to about $80 \mathrm{~m}$ (Paolucci et al. 2015; Gallipoli et al. 2014); a crosshole CH survey performed by the Emilia-Romagna Region (Martelli and Romani 2013), providing the $V s$ profile in the first $126 \mathrm{~m}$, just under the bedrock occurrence. As already
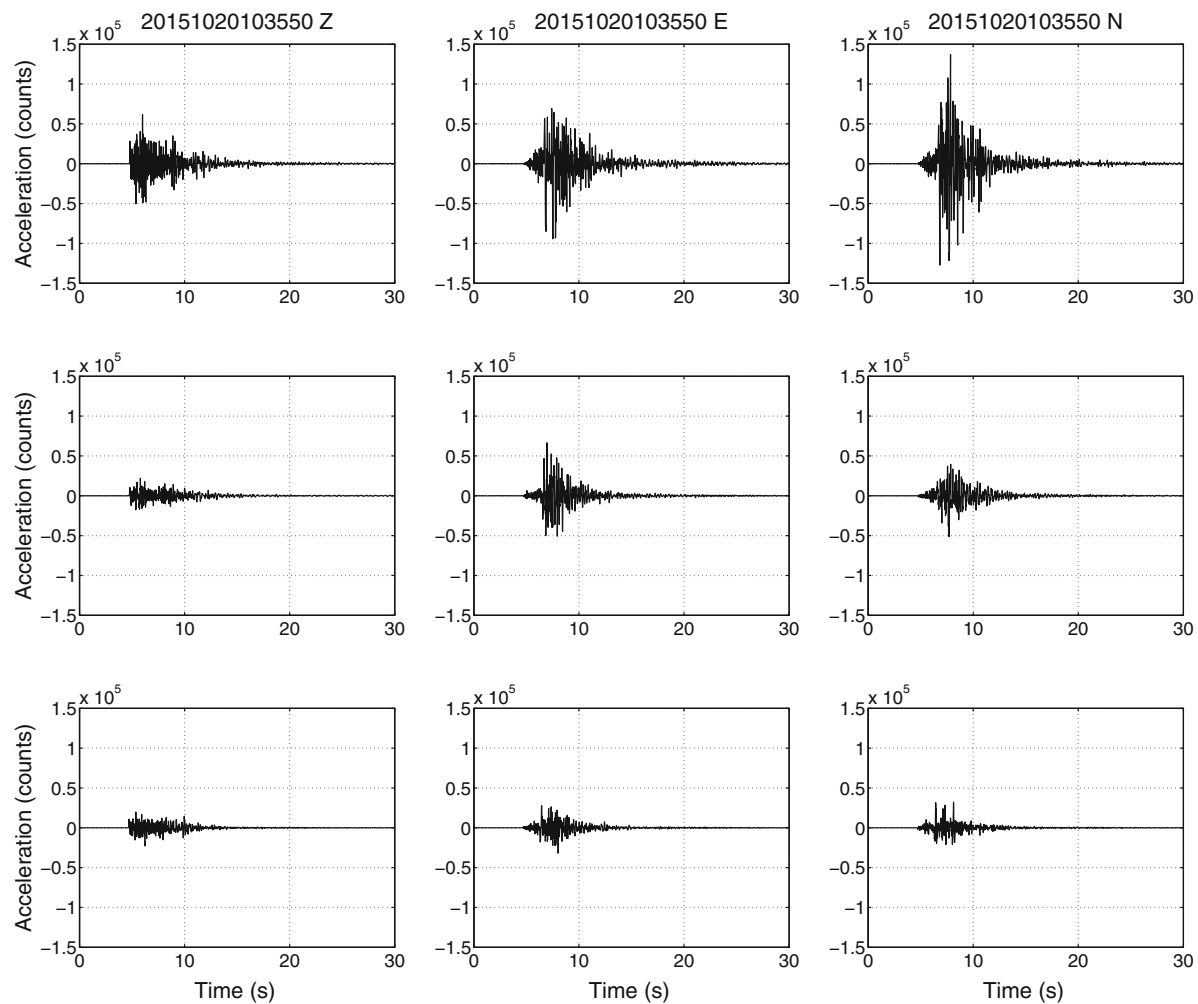

Fig. 2 Recordings of the October 20, 2015, 10:35:50, M = 3.5 event. From left to right: vertical, EW, and NS components. From top to bottom: recordings at surface, $\mathrm{z}=-31$ and $-126 \mathrm{~m}$. Values are in counts 

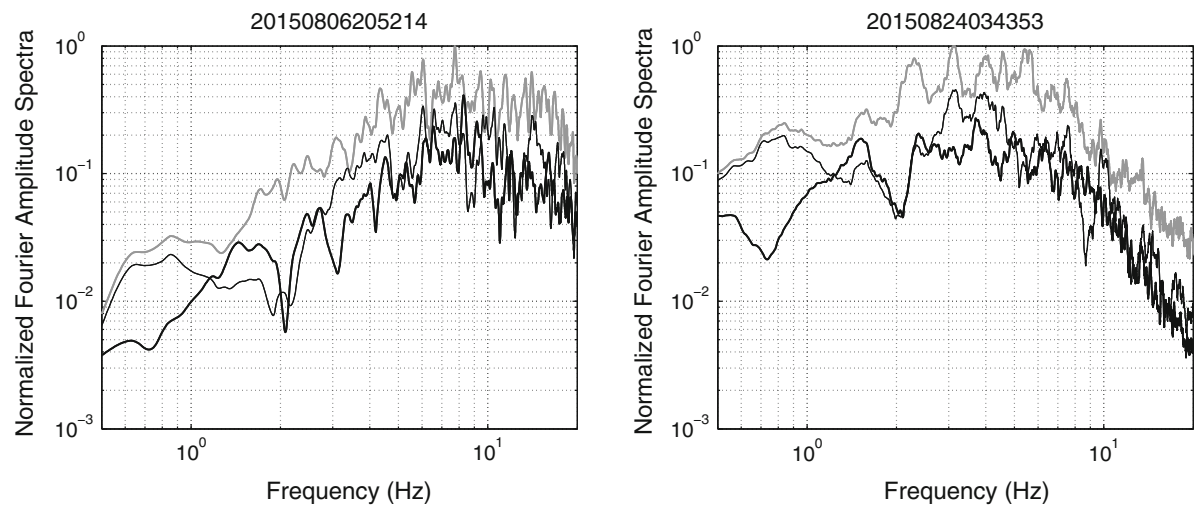

Fig. 3 Smoothed amplitude Fourier spectra (horizontal components) computed for 2 different events recorded at surface (grey curve), at $31 \mathrm{~m}$ depth (thin black curve), and at $126 \mathrm{~m}$ depth (thick black curve), respectively
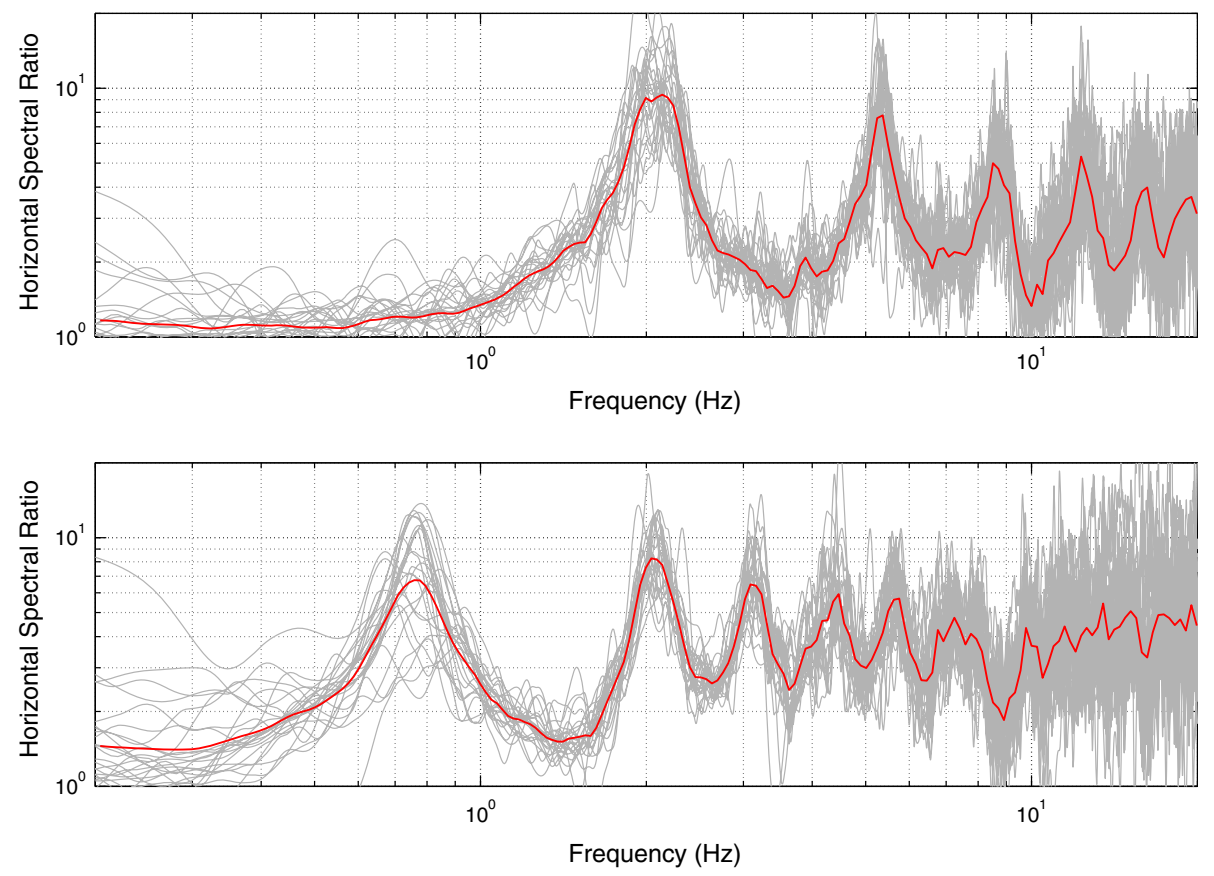

Fig. 4 Spectral ratios between amplitude Fourier spectra of the data recorded at surface and depth ( $z=-31$ and $-126 \mathrm{~m}$, top and bottom, respectively). Grey curves in the background show the spectral ratios (geometrical average of the two horizontal components) obtained for the 25 selected events while the red curve represents their arithmetic mean

mentioned, this profile has been validated within the InterPACIFIC project (Garofalo et al. 2016a, b). The available stratigraphic profile displays some discontinuities, corresponding to lithological transitions between silts, clay, and sands, in particular at depths of 5, 10, 25, $50,75,96 \mathrm{~m}$ and at $113 \mathrm{~m}$ with the top of the Pliocene marine bedrock occurrence. The $V s$ profile estimated by the $\mathrm{CH}$ survey (Fig. 5, blue bold curve) shows a general increase of $V s$ 


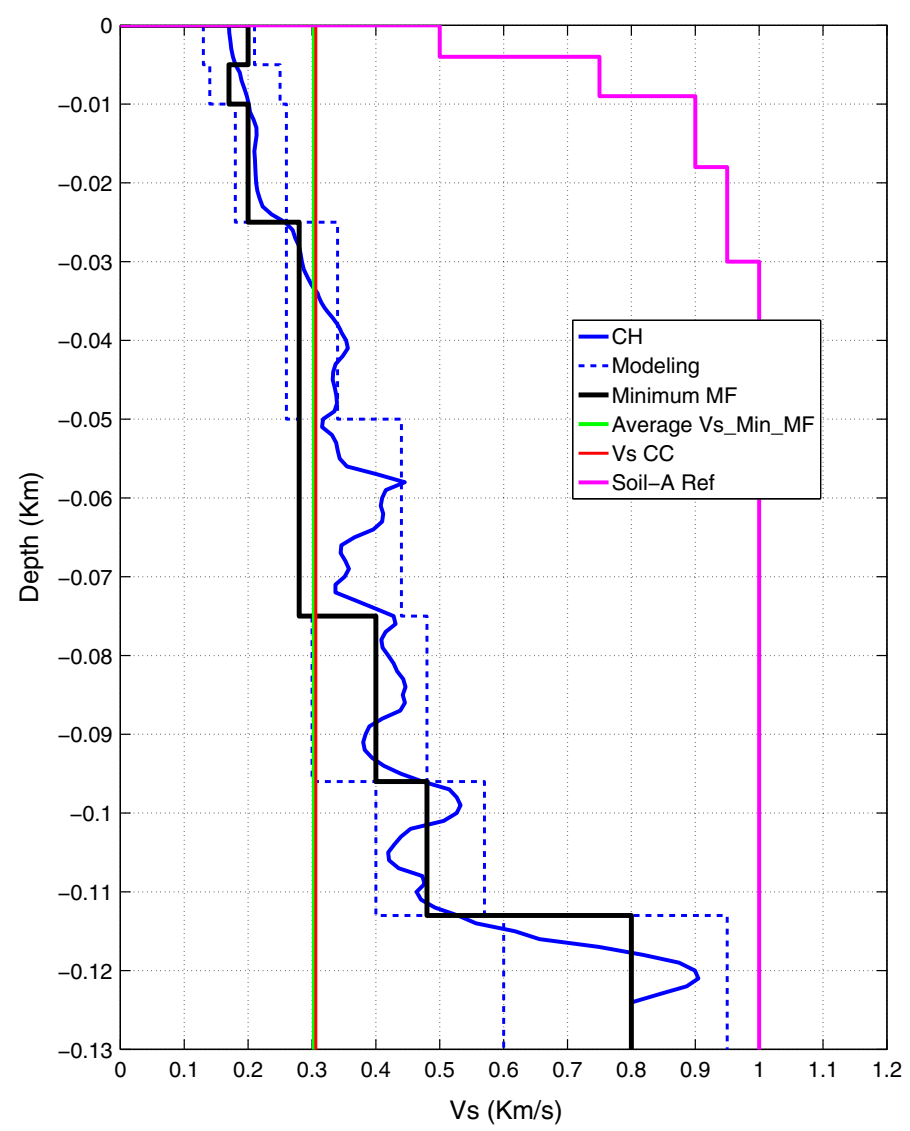

Fig. 5 Blue thick curve Vs profile from $\mathrm{CH}$ survey (Martelli and Romani 2013; Paolucci et al. 2015; Garofalo et al. 2016a, b). Blue dashed lines bounds of the Vs values within each layer of the profile. Black line $\mathrm{Vs}$ profile corresponding to the minimum MF in the interference functions. Green and red vertical lines harmonic average of the Vs model with the minimum MF and Vs corresponding to the cross correlation delay between earthquake recordings at surface and at $-126 \mathrm{~m}$ of depth, respectively. Magenta line virtual reference models, representing a class-A soil site

with depth with two jumps, one at about $90 \mathrm{~m}$, which corresponds to the transition from less consolidated to more consolidated sediments, and the other at $113 \mathrm{~m}$, which marks the roof of the consolidated marine deposits.

In order to emphasize the sensitivity of the interferometric functions to $V s$ variation, we considered the $V s$ profile resulting from the $\mathrm{CH}$ as reference and build up a set of compatible constant velocity layers models, with layer thickness determined from the stratigraphic profile and $V s$ values varying within bounds indicated by the blue dashed lines in Fig. 5 (corresponding to about $20 \%$ of the mean value provided by the $\mathrm{CH}$ in each layer). For each model, we computed the interferometric function and compared it with the experimental one.

The validation procedure followed two steps. We considered separately the shallower profile (until $31 \mathrm{~m}$ corresponding to the first sensor location) and then the remaining structure until $126 \mathrm{~m}$ of depth. Figure 6 shows in grey the interferometric functions obtained from all the considered variations (625 variations for the uppermost model in the 
top panel, and 868 variations for the remaining structure in the bottom panel) compared to the experimental interferometric function (in red). The modeled interferometric function corresponding to the minimum MF is shown in black in Fig. 6 while the corresponding $\mathrm{S}$-wave velocity profile is shown in black in Fig. 5 and listed in Table 2. This model features also a very good agreement with those obtained by different authors from invasive and non-invasive methods and compared in Garofalo et al. (2016b; Fig. 13).

Figure 6 emphasizes the sensitivity of the interferometric functions with respect to the variation in the velocity models. The residual of the best-fit curve is about $17 \%$ of the maximum residual found within the population of the examined models. In a future application of this approach, a more sophisticated method of inversion could be adopted.

The green and red lines on the left panel of Fig. 5 represents the harmonic average of the $V s$ model corresponding to the minimum MF and the $V s$ corresponding to the delay in the cross correlation between of the earthquake recordings at surface and at the deeper sensor, respectively. They differ of only $1 \%$, and this result confirms the robustness of the obtained Vs model.

Finally, the average shear wave velocity of the top $30 \mathrm{~m}$ (VS30) of the model corresponding to the minimum MF was estimated in about $210 \mathrm{~m} / \mathrm{s}$, corresponding to a class-C soil (CEN 2003). This value is in good agreement with the average value estimated by Garofalo et al. (2016b) by invasive and non-invasive methods (i.e. 209 and $218 \mathrm{~m} / \mathrm{s}$, respectively).

We can conclude that the velocity model obtained for the site of Mirandola has been well constrained by experimental data.

\section{Definition of the virtual reference site and evaluation of the site amplification at Mirandola}

A difficulty in the evaluation of the seismic site response by traditional methods (as RSSR) for sites like Mirandola, located within the alluvial plain, is the lack of reference sites. We overcame this difficulty by computing numerically the spectral ratio between the wavefield propagating through the obtained best-fit model and a virtual model which represents a class-A soil site. The latter model (shown in magenta in Fig. 5) represents a typical site of the North Apennine chain, with relatively low velocities at surface $(500 \mathrm{~m} / \mathrm{s})$ and a smooth increase of velocity with depth. At $30 \mathrm{~m}$ the velocity is $1000 \mathrm{~m} / \mathrm{s}$. The adopted values are consistent with those of the velocity profiles obtained from down-hole and cross-hole surveys performed by the Geological Seismic and Soil Survey of the Emilia-Romagna Region in areas where the Marnoso-Arenacea formation (Langhian-Tortonian) outcrops. The VS30 of the virtual reference site is $800 \mathrm{~m} / \mathrm{s}$, consistently with a class-A soil (CEN 2003).

Figure 7 shows the spectral ratio between seismograms computed for Mirandola using the $V s$ model corresponding to the minimum MF (see Sect. 4.2) and the virtual reference site. The resulting seismic response features an average level of amplification between 2 and 3 extending over the entire frequency band $0.5-3 \mathrm{~Hz}$ and shows two moderate peaks at about $0.8 \mathrm{~Hz}$ and $2.1 \mathrm{~Hz}$, respectively.

Using this curve to represent the spectral amplification at Mirandola, we can evaluate the site response in terms of acceleration response spectra and amplification factors, and compare those quantities to the same ones predicted by the Italian building code. To do that, we follow the standard procedure of the Indirizzi e criteri per la microzonazione 

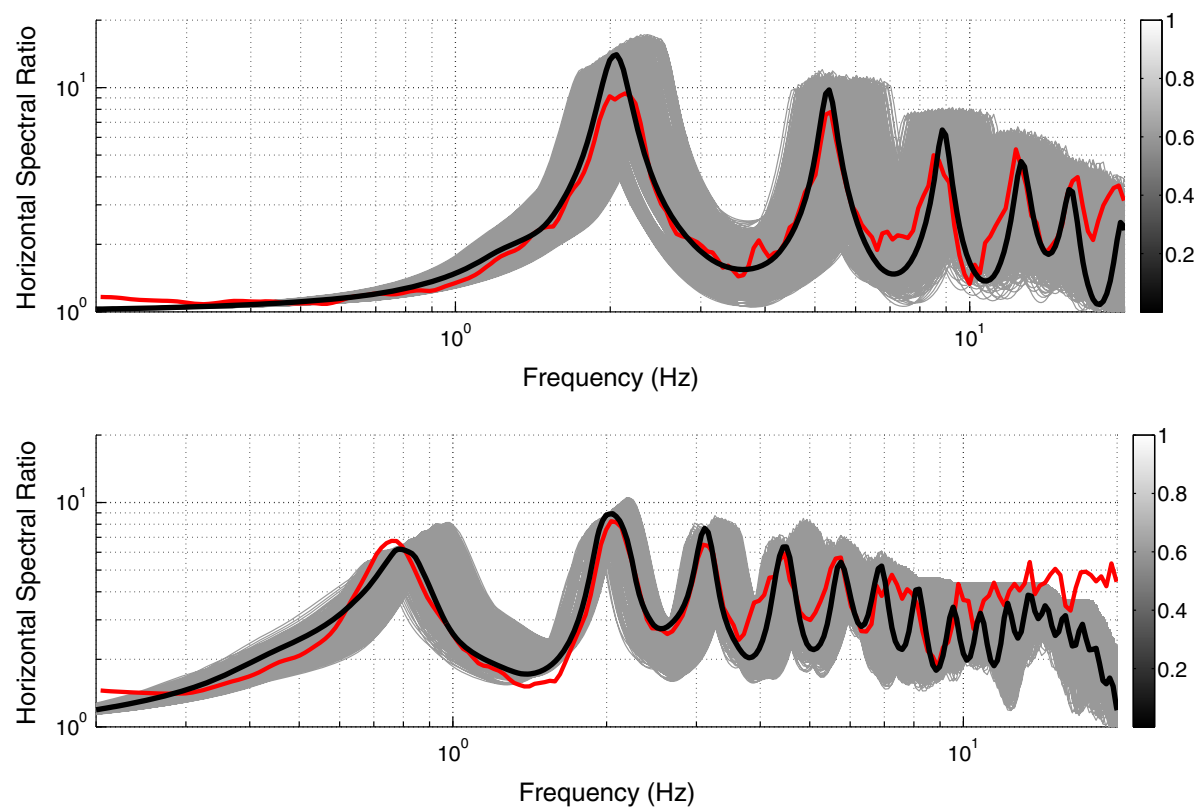

Fig. 6 Ratios between amplitude Fourier spectra of the synthetic data computed at surface and depth ( $\mathrm{z}=-31$ and $-126 \mathrm{~m}$, top and bottom, respectively). Grey curves in the background show the spectral ratios obtained from all the considered models, black thick curve is the synthetic interferometric function corresponding to the minimum MF compared with the experimental one (red curve)

Table 2 S-wave velocity model that best fits the empirical interferometric function

\begin{tabular}{lll}
\hline $\mathrm{z}(\mathrm{m})$ & $\mathrm{h}(\mathrm{km})$ & $\mathrm{Vs}(\mathrm{km} / \mathrm{s})$ \\
\hline 0 & 0.005 & 0.20 \\
-5 & 0.005 & 0.17 \\
-10 & 0.015 & 0.20 \\
-25 & 0.025 & 0.28 \\
-50 & 0.025 & 0.28 \\
-75 & 0.021 & 0.40 \\
-96 & 0.017 & 0.48 \\
-113 & 0.127 & 0.80 \\
\hline
\end{tabular}

From left to right: interface depth, layers thickness, Vs

sismica (Gruppo di Lavoro MS 2008). We first select a set of real accelerograms such that its average represents the seismic action at the specific site input and is spectrum-compatible with the acceleration response spectra of the Italian building code (NTC08, 2008). We decided to adopt the same time histories (see Table 3) used as seismic input in previous studies by Laurenzano et al. (2013a, b). Data have been downloaded from the ITACA database (ITACA Working Group 2016). Figure 8 (left panel) shows the response spectra of the 5 accelerograms and their mean.

We compute the site-specific acceleration response spectrum (Fig. 8, right panel) as a mean of the convolution of each seismic input with the site amplification curve calculated with respect to the virtual reference site. A specific smoothing procedure (Indirizzi e Criteri 


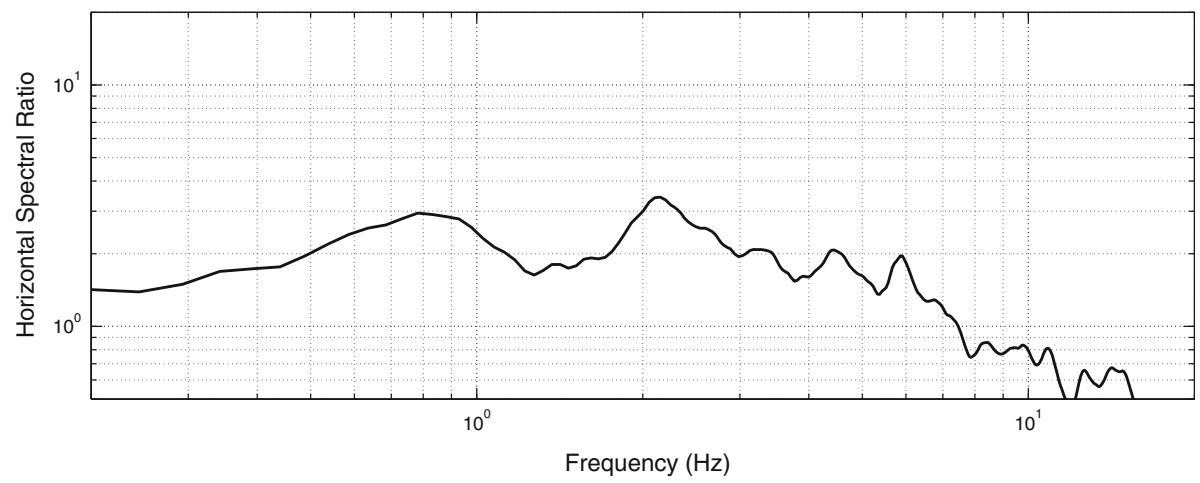

Fig. 7 Ratios between amplitude Fourier spectra of the data computed at surface for model corresponding to the minimum MF and the virtual reference site. The black curve represents the spectral amplification estimated for the Mirandola site as a result of this study

Table 3 Details of the time acceleration histories, which are used to represent the seismic action

\begin{tabular}{llllllr}
\hline Event & Date & Lat & Long & Mw & Station & R (km) \\
\hline Friuli (Italy) & $1977 / 09 / 16$ & 46.28 & 12.98 & 5.3 & SMT & 9.1 \\
Golfo di Patti (Italy) & $1978 / 04 / 15$ & 38.27 & 15.11 & 6.0 & NAS & 33.0 \\
Val Comino (Italy) & $1984 / 05 / 07$ & 41.70 & 13.86 & 5.9 & ATN & 10.3 \\
Umbria-Marche (Italy) & $1998 / 04 / 03$ & 43.19 & 12.76 & 5.1 & NCM & 5.2 \\
L'Aquila (Italy) & $2009 / 04 / 07$ & 42.38 & 13.38 & 4.6 & AQP & 0.7 \\
\hline
\end{tabular}

per la Microzonazione Sismica, Gruppo di Lavoro MS 2008) gives us the smoothed spectrum, which is described analytically by the four parameters $T_{0}, T_{A}, T_{B}, T_{C}$ and $T_{D}$.

The smoothing procedure includes the following steps:

- Estimating the periods TA and TV corresponding to the peak in the acceleration and velocity response spectra, respectively;

- Calculating the mean of the pseudo-acceleration response spectrum SA between 0.5 TA and 1.5 TA;

- Calculating the mean of the pseudo-velocity response spectrum SV between $0.8 \mathrm{TV}$ and $1.2 \mathrm{TV}$;

- Calculating the four parameters:

$$
T_{A}=2 \pi(S V / S A) ; \quad T_{B}=1 / 3 T c ; \quad T_{C}=2 \pi(S V / S A) ; \quad T_{D}=4 a g+1.6 ;
$$

where, $a g$ is the acceleration value at $\mathrm{T}=0 \mathrm{~s}$;

- Calculating the four spectra branches between $\mathrm{T}_{0}, \mathrm{~T}_{\mathrm{A}}, \mathrm{T}_{\mathrm{B}}, \mathrm{T}_{\mathrm{C}}$ and $\mathrm{T}_{\mathrm{D}}$ and $\mathrm{T}=4 \mathrm{~s}$, by applying the equations given by Gruppo di Lavoro MS (2008)

The smoothed spectrum can be compared to the spectra of the Italian building code NTC08 for different soil classes (Fig. 9, left panel). It is consistent with class-C soil spectrum up to a period of about $0.3 \mathrm{~s}$, but it features a narrower band plateau (between 0.15 and $0.3 \mathrm{~s}$ ). For periods greater than $0.45 \mathrm{~s}$ the branch of the curve follows the class-B soil spectrum of the Italian building code. 

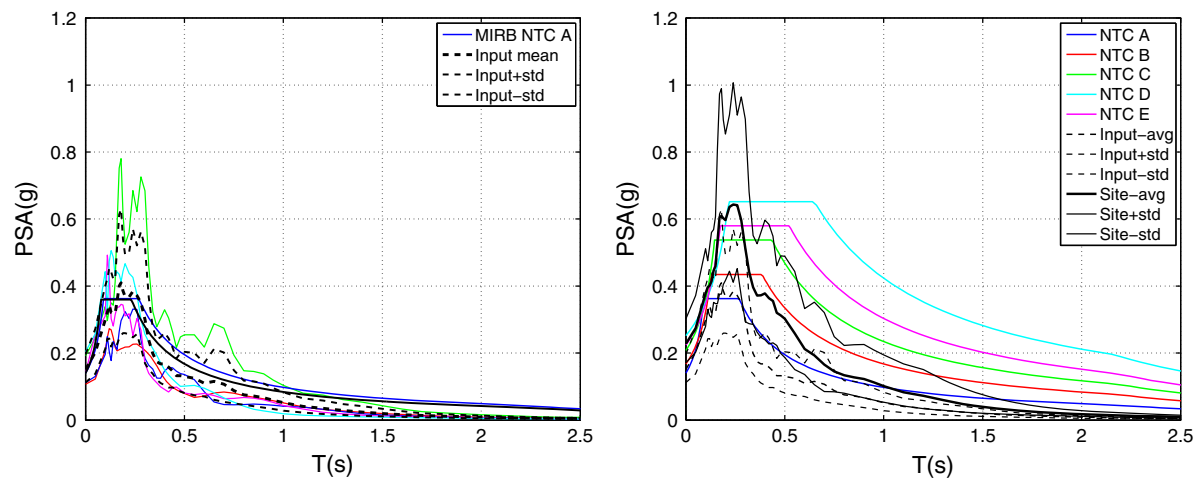

Fig. 8 Left panel acceleration response spectra of seismograms used as seismic input (colored curves), their mean and standard deviation (bold black dashed curves), smoothed spectra (black), and NTC8 8 (class-A) curve for Mirandola (blue). Right panel site acceleration response spectra (black curves) obtained for MIRB compared with the NTC-08 (Norme per le Costruzioni-NTC 2008) response spectra (colored lines) for the same locality. Black dashed curves indicate the seismic input (mean and standard deviation)
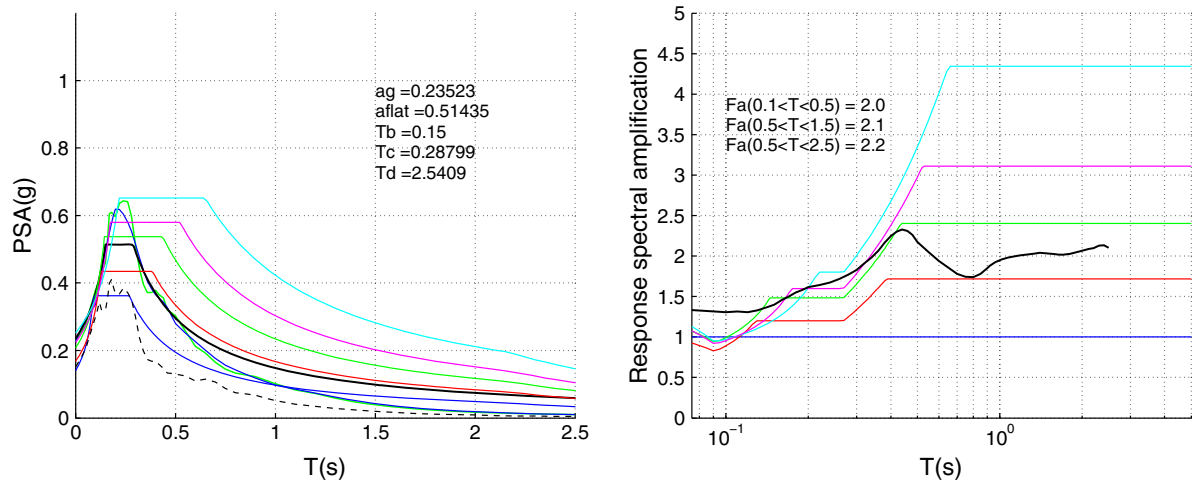

Fig. 9 Left panel smoothed response spectra (bold black lines) obtained for MIRB compared with the NTC08 (Norme per le Costruzioni-NTC 2008) response spectra (colored lines) for the same locality. Black dashed curves indicate the seismic input. Right panel site response spectral amplification (black curve) obtained for MIRB compared with the NTC-08. The average amplification factors obtained for three ranges of periods are also reported

In addition, we present the site response in terms of the ratio between the site-specific response spectrum and the seismic input. This amplification can be directly compared with that deduced from the NTC08 amplifications. Figure 9 (right panel) confirms that the amplification level is consistent with that of a class-C soil, especially for periods up to $\mathrm{T}=0.45 \mathrm{~s}$, while for higher periods the response spectral amplification lays between class-B and C soil spectra. Finally, we computed the amplifications factors $F a$ as the ratio between the spectral intensity (Housner 1952) of the accelerograms obtained at the site and the seismic input for different period ranges. Amplification factors lay between 2.0 and 2.2 for the three considered ranges of periods (Fa reported in Fig. 9, right panel). 


\section{Conclusions}

In this study we apply an original procedure that makes use of both numerical modeling methods and earthquake accelerometric data simultaneously recorded at surface and in borehole to characterize the seismic response of the site of Mirandola, located on the Po alluvial plane. For this station no reference sites can be identified, thus the standard RSSR approach, which requires a reference site at surface, is inapplicable. We exploit the interference between the up-going wavefield coming from a deep source and the downgoing wavefield reflected from the surface and recorded by a borehole receiver to validate the shallow $V s$ model down to the receiver depth. The wavefield interference at the receiver depth is computed as the ratio between the Fourier amplitude spectra of waveforms recorded at surface and at depth $z$ and is called interferometric function.

By comparing the interferometric functions computed through numerical modeling for a set of velocity models defined on the basis of a $\mathrm{CH}$ survey, with those calculated from recorded data we could refine and validate the local shear-wave velocity model. Being the interferometric function very sensitive to any variation of the shallow portion of the model, this approach proves to be effective and reliable for improving the velocity model, when simultaneous earthquake recordings at both surface and borehole are available.

We also use the numerical modeling to evaluate the local spectral amplification at Mirandola as the amplitude spectral ratio between synthetic accelerograms computed for the previously validated $V s$ model and a virtual reference model representative of a class-A soil site. Finally, following a standard procedure, we evaluate the site response in terms of acceleration response spectra and amplification factors and compare them to those predicted by the Italian building code. The results obtained in this study show that Mirandola features an amplification level consistent with that of a class-C soil up to a period of approximately $0.45 \mathrm{~s}$, while for higher periods, the amplification lays between class-B and C soils.

Acknowledgments This study has benefited from funding of the following projects: Projects S2-2012 and S2-2014, of the Italian Presidenza del Consiglio dei Ministri-Dipartimento della Protezione Civile (DPC); Project (Determinazione n. 18783, 18/12/2014) of Regione Emilia-Romagna, Servizio Geologico, Sismico e dei Suoli, Direzione Generale Ambiente e Difesa del Suolo e della Costa. This paper does not necessarily represent DPC official opinion and policies. Accelerometric recordings for MIRB station can bee freely downloaded from NISBAS_Network of Italian Surface-Borehole Accelerometers and Seismometers (http:// nisbas.crs.inogs.it, Mucciarelli et al. 2015) and from OASIS-the OGS Archive System of Instrumental Seismology (http://oasis.crs.inogs.it, Priolo et al. 2015). Synthetic seismograms have been computed by the Wavenumber Integration Method, with the computer code of the package Computer Programs in Seismology developed by R. B. Herrmann at St. Louis University (Herrmann 1996a, b). We also thank the two anonymous reviewers for their comments and suggestions, which have been really useful to improve our paper. In the meantime this paper is being printed, one of the author, i.e. Marco Mucciarelli, has passed away. The other authors would like to remind him as a great scientist, a precious colleague and a dear friend.

Open Access This article is distributed under the terms of the Creative Commons Attribution 4.0 International License (http://creativecommons.org/licenses/by/4.0/), which permits unrestricted use, distribution, and reproduction in any medium, provided you give appropriate credit to the original author(s) and the source, provide a link to the Creative Commons license, and indicate if changes were made.

\section{References}

Barnaba C, Laurenzano G, Moratto L, Sugan M, Vuan A, Priolo E, Romanelli M, Di Bartolomeo P (2014) Strong-motion observations from the OGS temporary seismic network during the 2012 Emilia sequence in northern Italy. Bull Earthq Eng 12(5):2165-2178. doi:10.1007/s10518-014-9610-4 
Borcherdt RD (1970) Effects of local geology on ground motion near San Francisco Bay. Bull Seismol Soc Am 60:29-61

CEN, European Committee for Standardisation TC250/SC8/(2003) Eurocode 8: design provisions for earthquake resistance of structures, Part 1.1: General rules, seismic actions and rules for buildings, PrEN1998-1

Gallipoli MR, Chiauzzi L, Stabile TA, Mucciarelli M, Masi A, Lizza C, Vignola L (2014) The role of site effects in the comparison between code provisions and the near field strong motion of the Emilia 2012 earthquakes. DOI, Bull Earthq Eng. doi:10.1007/s10518-014-9628-7

Garofalo F et al (2016a) InterPACIFIC project: comparison of invasive and non-invasive methods for seismic site characterization. Part I: Intra-comparison of surface wave methods. Soil Dyn Earthq Eng 82:222-240

Garofalo F et al (2016b) InterPACIFIC project: comparison of invasive and non-invasive methods for seismic site characterization. Part II: Inter-comparison between surface wave and borehole methods. Soil Dyn Earthq Eng 82:241-254

Govoni A, Marchetti A, De Gori P, Di Bona M, Lucente FP, Improta L, Chiarabba C, Nardi A, Margheriti L, Piana Agostinetti N, Di Giovambattista R, Latorre D, Anselmi M, Ciaccio MG, Moretti M, Castellano C, Piccinini D (2014) The 2012 Emilia seismic sequence (Northern Italy): imaging the thrust fault system by accurate aftershock location. Tectonophysics 622:44-55. doi:10.1016/j.tecto.2014.02.013

Gruppo di Lavoro MS (2008) Indirizzi e criteri per la microzonazione sismica. Conferenza delle Regioni e delle Province Autonome - Dipartimento della Protezione Civile, Roma, 3 vol. e CD-ROM

Herrmann RB (1996a) Computers program in seismology. An overview of synthetic seismogram computation, version 3.0. Department of Earth and Atmospheric Sciences, Saint Louis University

Herrmann RB (1996b) Computers program in seismology. Volume VI: wavenumber integration, version 3.0. Department of Earth and Atmospheric Sciences; Saint Louis University

Housner GW (1952) Spectrum intensity of strong motion earthquakes. In: Proceedings of the symposium on earthquakes and blast effects on structures. Earthquake Engineering Research Institute, California, pp 20-36

ISIDe Working Group (INGV) (2010) Italian seismological instrumental and parametric database. http:// iside.rm.ingv.it

ITACA Working Group (2016) ITalian ACcelerometric archive, version 2.1. doi:10.13127/ITACA/2.1

Laurenzano G, Priolo E, Barnaba C, Gallipoli MR, Klin P, Martelli L, Mucciarelli M, Romanelli M (2013a) Studio sismologico per la caratterizzazione della risposta sismica di sito ai fini della microzonazione sismica di alcuni comuni della Regione Emilia-Romagna. Atti del 32 Convegno Nazionale GNGTS, Tema 2, pp 247-252

Laurenzano G, Priolo E, Barnaba C, Gallipoli MR, Klin P, Mucciarelli M, Romanelli M (2013b) Studio sismologico per la caratterizzazione della risposta sismica di sito ai fini della microzonazione sismica di alcuni comuni della regione Emilia-Romagna - Relazione sull'attività svolta. Rel. OGS 2013/74 Sez. CRS 26, 31 luglio 2013

Malagnini L, Herrmann RB, Munafò I, Buttinelli M, Anselmi M, Akinci A, Boschi E (2012) The 2012 Ferrara seismic sequence: regional crustal structure, earthquake sources, and seismic hazard. Geophys Res Lett 39(19):L19302. doi:10.1029/2012GL053214

Martelli L, Romani M (2013) Microzonazione sismica e analisi della condizione limite per l'emergenza delle aree epicentrali dei terremoti della pianura emiliana di maggio-giugno 2012 (ordinanza del commissario delegato - presidente della Regione Emilia-Romagna n. 70/2012). Relazione illustrativa. Servizio geologico, sismico e dei suoli della Regione Emilia-Romagna. http://ambiente.regione.emiliaromagna.it/geologia/temi/sismica/speciale-terremoto/sisma-2012-ordinanza-70-13-11-2012-cartografia

Martelli L, Calabrese L, Ercolessi G et al (2013) Microzonazione Sismica dell'area epicentrale del terremoto della pianura emiliana del 2012. Atti $32^{\circ}$ Convegno Nazionale GNGTS, Trieste, 19-21 novembre 2013, sessione 2.2, 262-267

Moretti M, Abruzzese L, Abu ZN, Augliera P, Azzara R, Barnaba C, Benedetti L, Bono A, Bordoni P, Boxberger T, Bucci A, Cacciaguerra S, Calò M, Cara F, Carannante S, Cardinale V, Castagnozzi A, Cattaneo M, Cavaliere A, Cecere G, Chiarabba C, Chiaraluce L, Ciaccio MG, Cogliano R, Colasanti G, Colasanti M, Cornou C, Courboulex F, Criscuoli F, Cultrera G, D'Alema E, D’ Ambrosio C, Danesi S, De Gori P, Delladio A, De Luca G, Demartin M, Di Giulio G, Dorbath C, Ercolani E, Faenza L, Falco L, Fiaschi A, Ficeli P, Fodarella A, Franceschi D, Franceschina G, Frapiccini M, Frogneux M, Giovani L, Govoni A, Improta L, Jacques E, Ladina C, Langlaude P, Lauciani V, Lolli B, Lovati S, Lucente FP, Luzi L, Mandiello A, Marcocci C, Margheriti L, Marzorati S, Massa M, Mazza S, Mercerat D, Milana G, Minichiello F, Molli G, Monachesi G, Morelli A, Moschillo R, Pacor F, Piccinini D, Piccolini U, Pignone M, Pintore S, Pondrelli S, Priolo E, Pucillo S, Quintiliani M, Riccio G, Romanelli M, Rovelli A, Salimbeni S, Sandri L, Selvaggi G, Serratore A, Silvestri M, Valoroso L, Van der Woerd J, 
Vannucci G, Zaccarelli L (2012) Rapid response to the earthquake emergency of May 2012 in the Po Plain, northern Italy. Ann Geophys. doi:10.4401/ag-6152

Mucciarelli M, Diez Zaldivar ER, Gallipoli MR, Laurenzano G, Martelli L, Moratto L, Priolo E, Romanelli M, Stabile TA (2015) NISBAS-The Network of Italian Surface-Borehole Accelerometers and Seismometers. Atti del 34 Convegno Nazionale GNGTS, Tema 2, pp 135-142

Norme Tecniche per le Costruzioni (NTC) (2008). DM 14 gennaio 2008, Gazzetta Ufficiale, n. 29 del 4 febbraio 2008, Supplemento Ordinario n. 30, Istituto Poligrafico e Zecca dello Stato, Roma. www.cslp.it

Paolucci E, Albarello D, D’Amico S, Lunedei E, Martelli L, Mucciarelli M, Pileggi D (2015) A large scale ambient vibration survey in the area damaged by May-June 2012 seismic sequence in Emilia Romagna, Italy. Bull Earthq Eng 13(11):3187-3206. doi:10.1007/s10518-015-9767-5

Pieri M, Groppi G (1981) Subsurface geological structure of the Po Plain. Pubbl. 414, PF Geodinamica. C.N.R., p 23

Pitilakis K, Riga E, Anastasiadls A, Makra K (2015) New elastic spectra, site amplification factors and aggravation factors for complex subsurface geometry towards the improvement of EC8. In: 6th international conference on earthquake geotechnical engineering, New Zealand

Priolo E, Romanelli M, Barnaba C, Mucciarelli M, Laurenzano G, Dall'Olio L, Abu-Zeid N, Caputo R, Santarato G, Vignola L, Lizza C, Di Bartolomeo P (2012) The Ferrara Thrust Earthquakes of MayJune 2012-preliminary site response analysis at the sites of the OGS Temporary Network. Ann Geophys. doi:10.4401/ag-6172

Priolo E, Laurenzano G, Barnaba C, Bernardi P, Moratto L, Spinelli A (2015) OASIS-the OGS archive system of instrumental seismology. Seismol Res Lett 86(3):978-984. doi:10.1785/0220140175

Steidl JH, Tumarkin AG, Archuleta RJ (1996) What is a reference site? Bull Seismol Soc Am 86:1733-1748

Tertulliani A, Arcoraci L, Berardi M, Bernardini F, Brizuela B, Castellano C, Del Mese S, Ercolani E, Graziani L, Maramai A, Rossi A, Sbarra M, Vecchi M (2012) The Emilia 2012 sequence: a macroseismic survey. Ann Geophys 55:4. doi:10.4401/ag-6140

Vuan A, Klin P, Laurenzano G, Priolo E (2011) Far-source long-period displacement response spectra in the Po and Venetian Plains (Italy) from 3D wavefield simulations. Bull Seismol Soc Am 101(3):1055-1072 